Z Rheumatol 2012·71:436

DOI 10.1007/s00393-012-1013-9

(c) Springer-Verlag 2012
U. Müller-Ladner · U. Lange · E. Neumann · W. Hermann · I.H. Tarner

Abteilung für Rheumatologie und Klinische Immunologie, Lehrstuhl für Innere Medizin mit

Schwerpunkt Rheumatologie, Justus-Liebig Universität Gießen, Kerckhoff-Klinik, Bad Nauheim

\section{In memoriam Prof. Dr. Robert Dinser (1969-2012)}

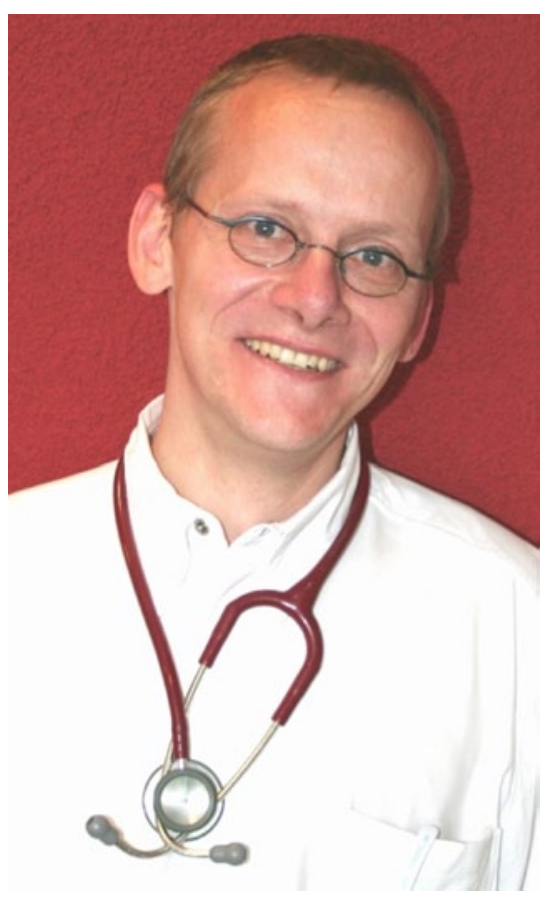

Am 08.05.2012 wurde Prof. Dr. med. Robert Dinser durch einen betrunkenen Autofahrer auf dem Nachhauseweg zu seiner Frau und seinen 4 Kindern tödlich verletzt und verstarb noch an der Unfallstelle. Die Rheumatologie verliert mit Herrn Kollegen Dinser einen der derzeit fähigsten wissenschaftlich und klinisch aktiven Kollegen, und sein Tod hinterlässt nicht nur an der Abteilung Rheumatologie und klinische Immunologie der Kerckhoff Klinik sowie der Justus-Liebig Universität Gießen nur sehr schwer füllbare Lücken.

Aufgewachsen in einer exzellenten wissenschaftlichen Umgebung als Sohn des Ordinarius für Biochemie in Münster, Prof. Kreße, entdeckte er schon früh seine Liebe zur Wissenschaft. Hinzu kam sein nachhaltiges Interesse an der Heilung kranker Menschen, das ihn zum Studium der Humanmedizin an der Ruhr-Universität Bochum leitete und 1996 zum Staatsexamen führte. Schon zu diesem Zeitpunkt bis zuletzt sah er sich als typischer Verteter des „clinical scientist“, was sich auch in seiner Promotionsarbeit an der Université Louis Pasteur in Strasbourg bei Prof. Imbs zum Thema „The angiotensin I converting enzyme in the renal cortex as a limiting factor of the kidney-based renin-angiotensin system. Methodological and functional aspects" widerspiegelt. Nach weiteren klinisch-wissenschaftlichen Stationen in Köln an der medizinischen Klinik II bei Prof. Krone, dem Institut für Biochemie II bei Prof. Paulsson und der Medizinischen Klinik I der Universität Homburg/Saar bei Prof. Pfeundschuh kam er dann 2005 nach Bad Nauheim, um dort nicht nur seine Ausbildung zum Rheumatologen zu vollenden, sondern sich auch seinem wissenschaftlichen Gebiet der Matrix- und Knorpelzellforschung sowie der Gelenkregeneration am Tiermodell intensiv zu widmen. Im Jahr 2008 erfolgte dann die Habilitation zum Thema „Pathogenese von mit Cartilage Oligomeric Matrix Protein (COMP) assoziierten Chondrodysplasien“, und 2011 wurde er aufgrund seiner exzellenten wissenschaftlichen Leistungen, aber auch aufgrund der ausgesprochenen Anerkennung durch die Studenten in der Lehre zum außerplanmäßigen Professor der Justus-Liebig Universität Gießen ernannt. Bis zuletzt war sein Schaffen geprägt durch seinen stets wachen, innovativen und interaktiven Geist in Klinik und Forschung, und es wird uns eine Ehre sein, seine vor Kurzem erst eingeworbenen Projekte bei der DFG und der EU erfolgreich weiterzuführen und in seinem Sinne zu neuen Erkenntnissen beizutragen.

\section{Korrespondenzadresse}

Prof. Dr. U. Müller-Ladner

Abteilung für Rheumatologie und Klinische Immunologie, Lehrstuhl für Innere Medizin mit Schwerpunkt Rheumatologie, Justus-Liebig Universität Gießen, Kerckhoff-Klinik Benekestr. 2-8, 61231 Bad Nauheim u.mueller-ladner@kerckhoff-klinik.de 